\title{
BMJ Open Systematic review of rehabilitation intervention outcomes of adult and paediatric patients with infectious encephalitis
}

\author{
Shanice Christie, ${ }^{1,2,3}$ Vincy Chan, ${ }^{1,3,4}$ Tatyana Mollayeva, ${ }^{1,3,4}$ Angela Colantonio ${ }^{3,4,5}$
}

To cite: Christie S, Chan V, Mollayeva T, et al. Systematic review of rehabilitation intervention outcomes of adult and paediatric patients with infectious encephalitis. BMJ Open 2018;8:e015928. doi:10.1136/ bmjopen-2017-015928

- Prepublication history and additional material for this paper are available online. To view please visit the journal (http:// dx.doi.org/10.1136/bmjopen2017-015928).

Received 24 May 2017 Revised 21 March 2018 Accepted 3 April 2018

Check for updates

${ }^{1}$ Acquired Brain Injury Research Lab, University of Toronto, Toronto, Ontario, Canada ${ }^{2}$ Dalla Lana School of Public Health, University of Toronto, Toronto, Ontario, Canada ${ }^{3}$ Toronto Rehabilitation Institute, University Health Network, Toronto, Ontario, Canada ${ }^{4}$ Rehabilitation Sciences Institute, University of Toronto, Toronto, Ontario, Canada ${ }^{5}$ Department of Occupational Science and Occupational Therapy, University of Toronto, Toronto, Ontario, Canada

Correspondence to Shanice Christie; shanice.christie@mail.utoronto. ca

\section{ABSTRACT}

Objective Although a range of rehabilitation interventions have been applied to restore function after infectious encephalitis, there is a lack of literature summarising the benefits of these interventions. This systematic review aims to synthesise current scientific knowledge on outcome measures following rehabilitative interventions among children and adults with infectious encephalitis, with a specific focus on the influence of the age, sex, baseline status and intervention type.

Search strategy Five scholarly databases (MEDLINE, Embase, PsycINF0, CINAHL and Cochrane Central Register of Controlled Trials), three sources of grey literature (Google, Google Scholar and Grey Matters) and reference lists of included publications were systematically searched. Literature published before 15 December 2017 and focused on patients with infectious encephalitis in any rehabilitation setting were included. Quality assessment was completed using the Downs and Black rating scale. Results Of the 12737 reference titles screened, 20 studies were included in this review. All of the studies had sample sizes of less than 25 patients and received a score of less than 15 out of 31 points on the Downs and Black rating scale. Findings showed a variety of interventions has been applied to alleviate sequelae from infectious encephalitis, including using cognitive therapy (nine studies), behavioural therapy (five studies), physical therapy (two studies) or two or more therapies (four studies). There was inconclusive evidence on the effect of sex, age and baseline functional abilities on outcomes. Due to clinical and methodological heterogeneity between studies, meta-analyses were not performed.

Conclusion Evidence suggests the potential for a beneficial effect of rehabilitation interventions in patients with infectious encephalitis. Future research is required to identify all effect modifiers and to determine the effect of time in the natural course of recovery. An enhanced set of known effect modifiers will support the process of future evaluation of a client-centred rehabilitation intervention. Trial registration number CRD42015029217.

\section{INTRODUCTION}

Infectious encephalitis is an inflammatory disease of the brain membrane and parenchyma due to infectious agents (ie, virus, bacteria, fungi and parasites). ${ }^{1}$ These

\section{Strengths and limitations of this study}

This review is the first to identify outcomes of various rehabilitative interventions in patients with infectious encephalitis and represents a starting point to help close the knowledge gap at a clinical level.

- This review has a stringent methodology including high sensitivity and specificity of search terms and clear inclusion and exclusion criteria.

- A limitation of this review is that most studies used a case series/study or observational design that is subject to bias and confounding.

- The scarcity of studies and/or data that measured standardised indicators of rehabilitation outcomes with regards to patients diagnosed with infectious encephalitis is a limitation.

Studies with high heterogeneity and varying design may limit the quality of evidence from this review.

infectious agents may influence the central nervous system function and can cause significant chronic neurological deficits, including speech or hearing deficits, seizures, altered mental status and, in more severe cases, loss of consciousness. ${ }^{1}$ Viral aetiologies account for $32 \%-57 \%$ of infectious cases ${ }^{2}$ of encephalitis that come to medical attention while other infectious, postinfectious and non-infectious aetiologies represent a smaller proportion of all diagnosed cases. ${ }^{3-6}$

Despite relatively low age-specific incidence rates for encephalitis, ranging from 3.24 per 100000 individuals (5-19 years of age) to 15.7 per 100000 individuals (75-79 years of age), ${ }^{357}$ compared with other acquired brain injurie (eg, traumatic brain injury (TBI) or non-TBI (ie, stroke) $),{ }^{8-10}$ the hospitalisation cost of this condition and its related sequelae are significant. ${ }^{11}$ In the USA, an estimated healthcare cost of encephalitis-associated hospitalisations was US $\$ 650$ million between the period of 1988 and 1997 and increased to US $\$ 2.0$ billion between 1998 and $2010 .{ }^{412}$ Likewise, the cost of encephalitis hospitalisation 
to the National Health Service in England has been estimated to be as high as US $\$ 60$ million per year. ${ }^{7}$

In addition to the direct healthcare costs, encephalitis remains a public health issue of a greater importance due to its associated morbidity and mortality. ${ }^{13}$ In terms of the related sequelae that follows the diagnosis of infectious encephalitis, it is reported that nearly half of the longterm survivors (follow-up time $\geq 12$ months) of childhood encephalitis experienced some form of a neurodevelopmental deficit. ${ }^{14}$ The most commonly reported sequelae included developmental delay (35.0\%), abnormal behaviour $(18.0 \%)$ and intellectual deficit $(17.5 \%) .{ }^{14}$

Certain aetiologies of encephalitis are more severe than others, with mortality rates varying between $10 \%$ and $30 \% .{ }^{15}$ For example, herpes simplex virus (HSV) encephalitis, a common type of infectious encephalitis, has a mortality rate of $5 \%-20 \%$ when an antiviral treatment is applied and up to $70 \%$ with no availability of acyclovir. ${ }^{16}$ Among those who survive, level of morbidities differ considerably, with an estimated $20 \%-60 \%$ of survivors reported to have chronic deficits, ${ }^{15}{ }^{17-19}$ including neurological impairments, movement disorders, aphasia, behavioural abnormalities and cognitive deficits. ${ }^{20-22}$ The recovery from encephalitis varies from a rapid and complete recovery within days to weeks ${ }^{2324}$ to a prolonged or incomplete recovery, ${ }^{25}{ }^{26}$ for which rehabilitation, as a basic foundation of care, is needed.

Despite the number of persistent deficits associated with infectious encephalitis, outcomes following rehabilitative interventions for patients diagnosed with infectious encephalitis are sparsely documented. Earlier studies focused on the epidemiology and rehabilitation outcomes of patients with encephalitis have acknowledged the absence of this patient population in inpatient rehabilitation programmes and the growing importance of admitting such patients. ${ }^{21} 27$

While examining rehabilitation outcomes of this population, it is also important to identify any differences and similarities in rehabilitation outcomes among male and female patients, as such differences have been documented in other patient populations. ${ }^{28}{ }^{29}$ For example, differences in the risk of developing post-traumatic stress disorder ${ }^{30}$ symptoms manifestation and severity between sexes ${ }^{31}$ and how well males and females respond to intervention ${ }^{32} 33$ and seek healthcare ${ }^{34}$ have all been discussed in current literature. In addition to potential sex differences in outcomes, previous studies have noted patient's age ${ }^{3536}$ baseline status $^{37} 38$ and type of applied intervention type (ie, physical therapy and cognitive therapy) as being associated with differences in rehabilitation outcomes. ${ }^{38}$

To the best of our knowledge, there is currently no systematic review on rehabilitation outcomes among patients with residual impairments of neurological functions following infectious encephalitis. Thus, using a best evidence synthesis approach, ${ }^{39}$ we aimed to: (1) summarise evidence of efficacy of interventions and associated rehabilitative outcomes within observational and experimental studies among children and adult patients with a primary diagnosis of infectious encephalitis; (2) describe results taking sex, age, baseline patients' characteristics and type of intervention into consideration; and (3) discuss future directions for research on rehabilitation outcomes of infectious encephalitis.

\section{METHODS}

This review was conducted in compliance with the Preferred Reporting Items for Systematic Reviews and Meta-Analyses as shown in figure $1 .^{40}$ The protocol for this systematic review was registered with the International Prospective Register of Systematic Reviews ${ }^{41}$ on 13 November 2015 (registration number CRD42015029217) and can be accessed at http://bmjopen.bmj.com/ content/6/3/e010754.full.

\section{Patient and public involvement}

There were no patients or applicable public involved in this review.

\section{Inclusion and exclusion criteria}

All studies that reported outcome data of rehabilitation interventions delivered to patients with a primary diagnosis of infectious encephalitis in an inpatient, outpatient or community rehabilitation setting were considered eligible in this review. We used the WHO's definition of 'rehabilitation' as 'any intervention that includes a process aimed at enabling patients to reach and maintain either their optimal physical, sensory, intellectual, psychological, or social functional levels by providing disabled patients with the tools they need to attain independence and self-determination'. ${ }^{42}$ All English-language peer-reviewed studies published before 15 December 2017 were considered eligible. We included original studies of all methodology hierarchies: experimental (ie, randomised control trials (RCTs) and pseudo-RCTs), comparative (ie, concurrent or historical control, cohort, case-control and interrupted time series) and other observational (ie, case series and pretest/post-test) studies.

The following exclusion criteria for the full-text screen were applied: (1) theoretical articles or review of treatment approaches; (2) studies describing pharmacological-based interventions not focused on rehabilitation as defined by the WHO; (3) studies not providing predata/ postdata of intervention; and (4) studies not presenting results using patient outcome measures (ie, functional measures and neuropsychology scores). Figure 1 displays the study selection process.

\section{Search strategy}

Five electronic databases were searched for studies published before 15 December 2017:

1. MEDLINE In-Process \& Other Non-Indexed Citations and MEDLINE (from 1946).

2. Embase (from 1974).

3. PsycINFO (from 1805). 


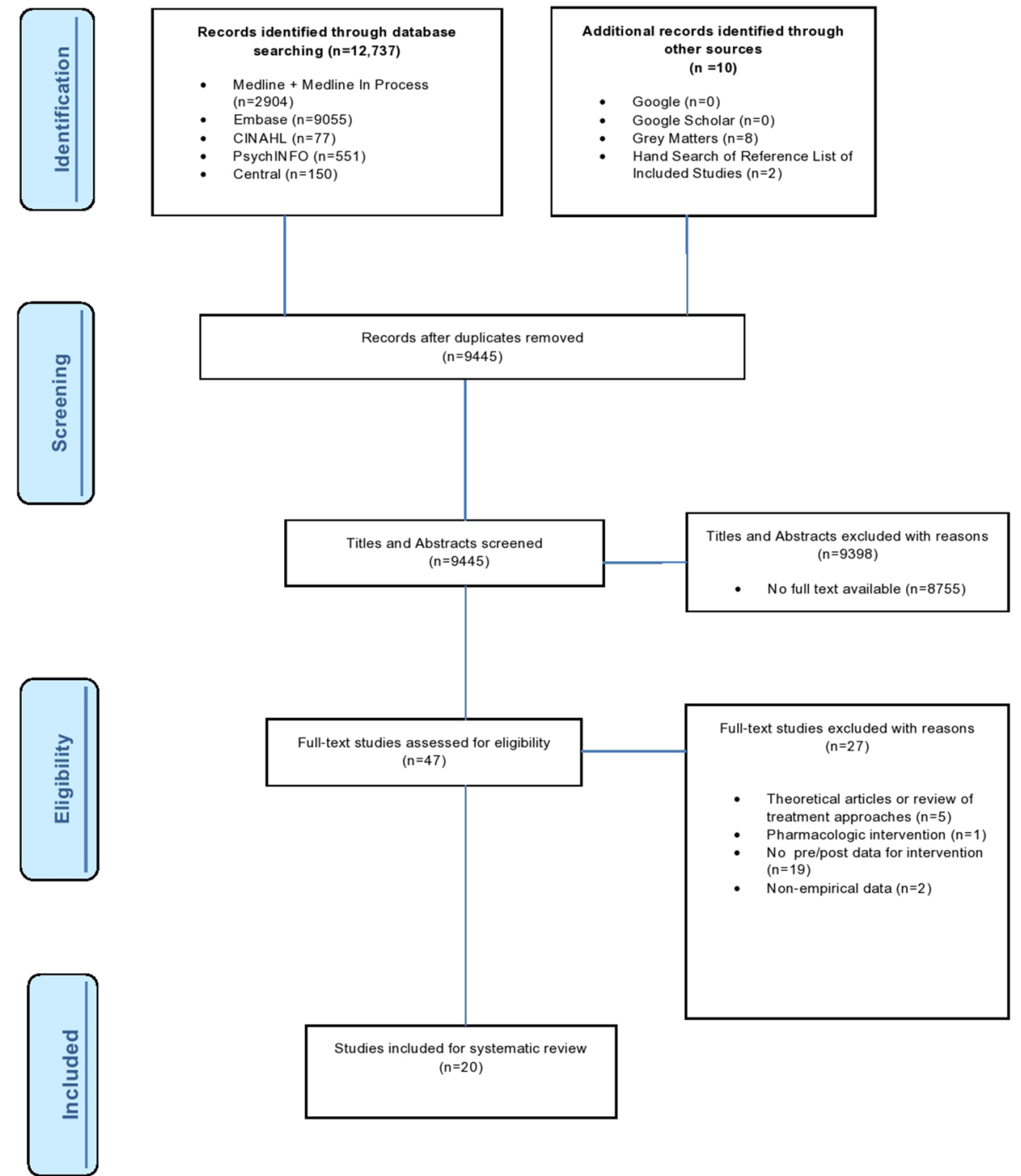

Figure 1 Our search yielded 12737 citations, with an additional eight records identified from a grey literature database and two by hand-searching the reference lists of included studies. Figure 1 details our search and selection process. We selected reviews that, based on our inclusion criteria, had a full-text version available and examined a type of a rehabilitation intervention administered to patients with infectious encephalitis and excluded records that were (1) theoretical articles or review of treatment approaches; (2) studies describing pharmacological-based interventions not focused on rehabilitation as defined by the WHO; (3) studies not providing predata/postdata of intervention; and (4) studies not presenting results using patient outcome measure. We identified 20 studies that met both first and second screen criteria.

4. CINAHL (from 1981).

5. Cochrane Central Register of Controlled Trials (from 2005).

The search strategy presented in online supplementary file 1 was derived using relevant published reviews as guides. ${ }^{434}$ The various search terms were categorised from two main terms: (1) encephalitis and (2) rehabilitation. The concept 'encephalitis' included the proxy terms for encephalitis such as 'encephaliti*', 'encephalopath*', 'Rasmussen* syndrome' and 'brain inflammation'. These proxy terms were included to increase the likelihood of capturing all studies that encompassed patients with infectious encephalitis. The second concept, 'rehabilitation', purposely included various types of rehabilitation therapies (ie, physical, occupational and speech-language) in order to capture a comprehensive list of rehabilitation services used on patients with infectious encephalitis. Additional proxy terms for the 'rehabilitation' concept were used, including 'length of stay', 'recovery of function', 'functional outcome', 'functional independence measure', 'functional recovery', 'discharge destination' and 'discharge status.' This ensured all studies focused on reporting rehabilitation outcomes from different types of rehabilitative interventions were included.

All databases were systematically searched on 1 June 2015; an update to searches was carried out on 15 December 2017. Grey literature was searched using Google, Google Scholar and 'Grey Matters, A Practical Search Tool for Evidence-Based Medicine'. Grey literature for this search was defined as 'document types produced on all levels of government, academics, business and industry in print and electronic formats that 
are protected by intellectual property rights, of sufficient quality to be collected and preserved by libraries and institutional repositories, but not controlled by commercial publishers'. ${ }^{45}$ As advised by the consulted information specialist (JB), the first 50 results were scanned for each grey literature source. In addition, the reference lists of studies passing the second screen were hand-searched on. Results of the eligible studies were saved in the electronic reference management system EndNote x7.

\section{Study selection}

A two-stage screening process for selecting eligible studies was undertaken by two reviewers (SC and $\mathrm{TM}$ ). The title and abstract screen was conducted on all retrieved studies. In order for a study to pass the first screen, the study must have had a full-text version available and examined a type of a rehabilitation intervention administered to patients diagnosed with infectious encephalitis. Studies that met the first screen inclusion criteria were then included for the second screen, a full-text screen. The same two reviewers independently assessed all fulltext studies against the exclusion criteria. Studies failing to meet the inclusion criteria were excluded, with reasons listed in figure 1.

\section{Data extraction}

Two reviewers (SC and TM) independently extracted data using a predefined table adapted from Mollayeva $e t a t^{46}$ as shown in table 1. Table 1 displays data as categorised by study design and included data on the authors (year), country, rehabilitation setting, study design characteristics (objectives, intervention type and level of evidence), inclusion/exclusion criteria, participant characteristics (sample size, attrition rate, age and sex of the population, time since infection, infectious agent, outcome measures, statistical method, preintervention/postintervention scores and list of other co-occurring intervention. The age of the population was categorised as paediatric population ( $\leq 19$ years old) and adult population ( $>19$ years old), based on the WHO age categories. ${ }^{47} 48$

\section{Data analysis}

The quality of the included studies was assessed using the Downs and Black rating scale as shown in table $2 .{ }^{49}$ This tool was previously used in studies focusing on rehabilitation interventions in patients with acquired brain injury. ${ }^{50}$ This tool consists of 27 questions grouped into five subscales allowing assessment of the: (1) overall quality of the study, (2) external validity, (3) study bias, (4) confounding and selection bias and (5) power analysis. Most of the scores range from 0 to 1, except for one item on the reporting confounders subscale that ranges from 0 to 2, and for one item at the power of the study subscale that ranges $0-5$. The maximum score is 31 , where a higher score indicates better methodological quality.

\section{Data synthesis}

A best-evidence synthesis approach that integrated findings from studies with sufficient quality through a tabulation and qualitative description process was used in data synthesis. ${ }^{41}$ This approach took into consideration that if included studies are not high in internal and external validity, then a careful analysis of the less well-designed studies has to be performed, in order to understand if there was enough information to come to a clinically meaningful conclusion.

\section{RESULTS}

\section{Literature search and quality assessment}

A total of 12737 reference titles were identified from a database search (MEDLINE: $n=2904$, Embase: $n=9055$, CINAHL: $\mathrm{n}=77$, PsychINFO: $\mathrm{n}=551$, Central: $\mathrm{n}=150$ ), and 10 studies were identified through Grey Matters and Google. After duplicates were removed, 9477 titles an abstracts were reviewed for potential inclusion. After the first title and abstract screen, 47 studies were identified as eligible and ultimately 20 studies were included after a second full-text screen was conducted as shown in figure $1 .{ }^{21}{ }^{52-70}$ The included studies featured 14 case reports, ${ }^{52} 53$ 57-59 61 63-70 three case series, ${ }^{566062}$ one randomised crossover study ${ }^{54}$ and two cohort studies. ${ }^{2155}$ All the identified studies had sample sizes less than 25. ${ }^{21}$ 47-51 57-70 Based on the Downs and Black rating scale, all 20 studies received a score of less than 15 out of the possible 31 points (table 2)..$^{214-5157-70}$

\section{Study characteristics}

Studies including paediatric populations (aged $\leq 19$ years)

Three studies (five participants in total) in this review focused specifically on paediatric participants, one being a cohort design $^{21}$ and the other two as case series. ${ }^{52} 53$ Baseline assessment varied across the three studies with one study using two neuropsychological test items (the Children's Orientation and Amnesia Test and the McCarthy scale of children's abilities) to assess the cognitive status of the patient. ${ }^{21}$ The other two studies did not specify a standardised tool that measured the severity of encephalitis' sequelae at baseline. ${ }^{52} 53$

Rehabilitation outcomes of these paediatric patients were reported using functional measures. ${ }^{2152} 53$ As none of the studies included had a follow-up assessment after discharge from rehabilitation, the long-term improvements from the rehabilitation intervention were not assessed.

\section{Studies including adult population ( $>19$ years old)}

Of the 20 studies (37 participants in total), 19 included adult patients. ${ }^{21}$ 53-70 Two studies had a cohort design, ${ }^{2155}$ one had a randomised crossover design, ${ }^{54}$ while the remainder were either case series ${ }^{535}$ or single case reports. ${ }^{57-70}$ There was a variety of agents that produced encephalitis, with the majority of studies looking at the effectiveness on interventions targeting sequelae of HSV encephalitis in 15 out of 37 adults.

A range of neuropsychological assessments has been used to measure the severity of functional impairment 


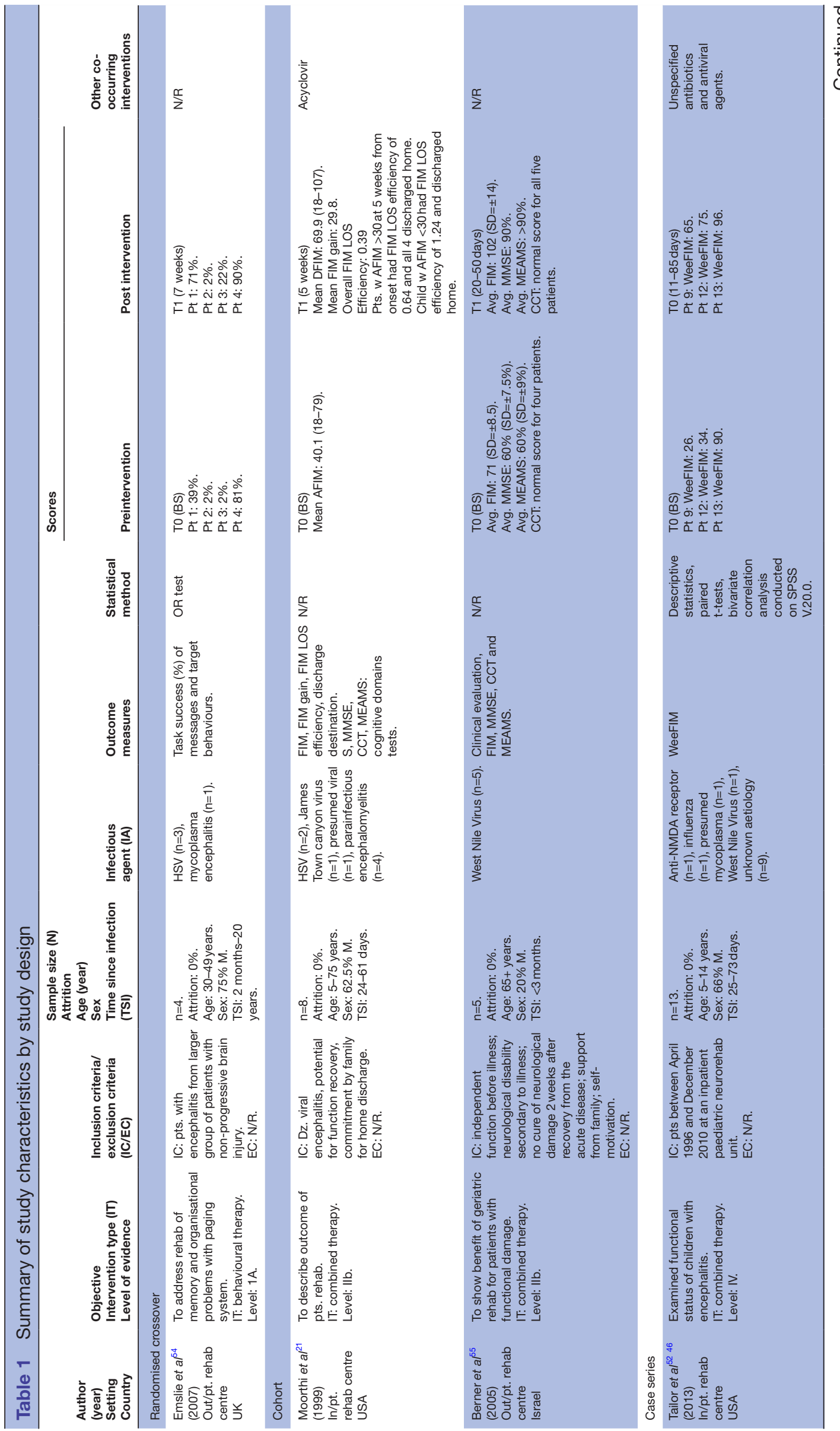

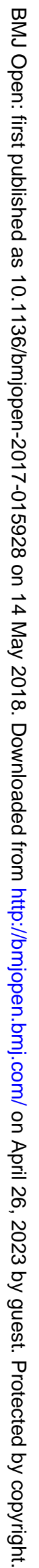




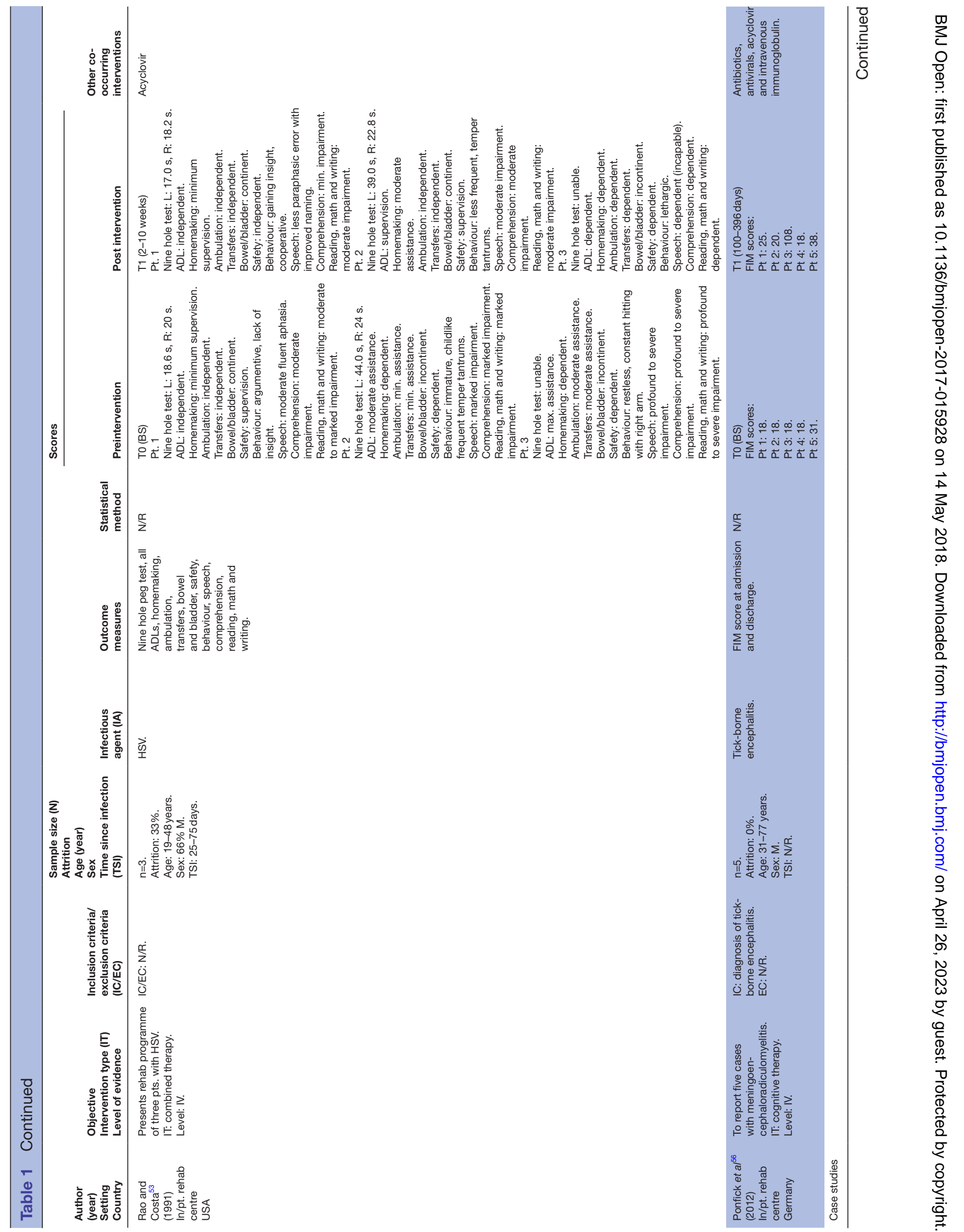




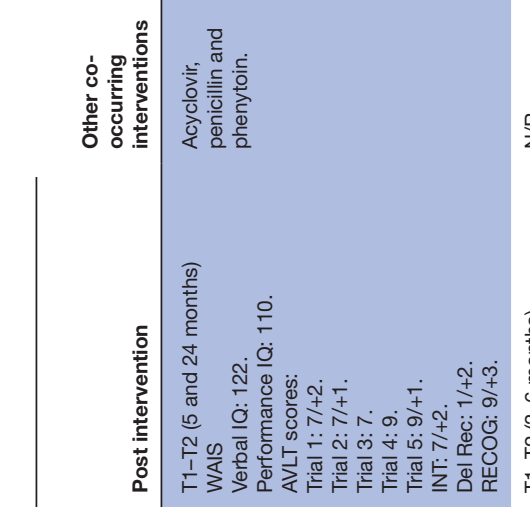

$\stackrel{q}{z}$

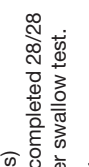

㟧

$\frac{3}{\frac{0}{10}}$
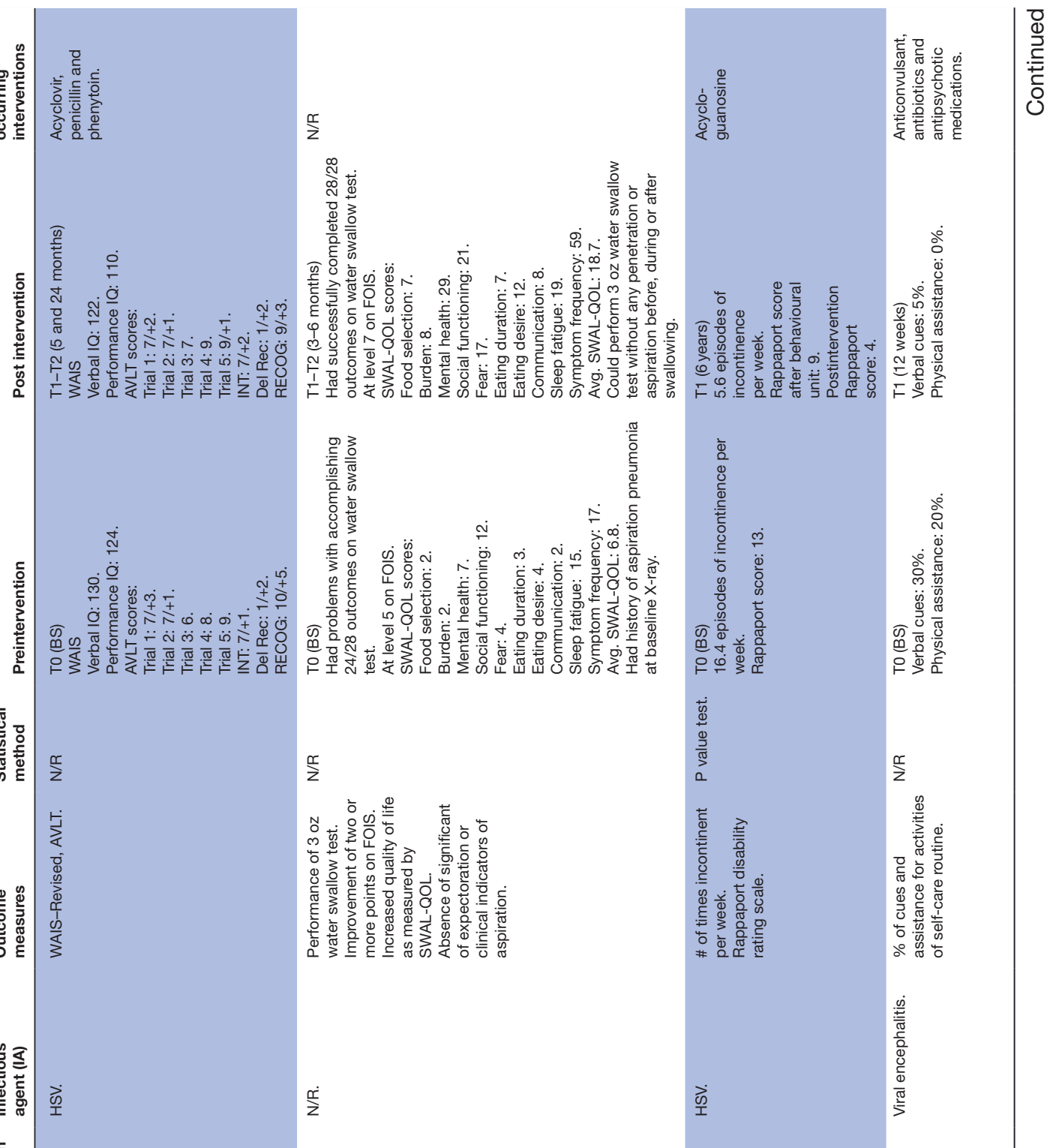

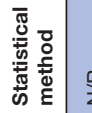

$\frac{\Upsilon}{z}$

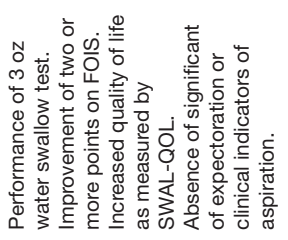

$\frac{\dot{s}}{2}$

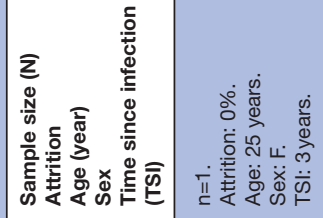

z

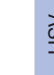

$\stackrel{\square}{\underline{2}}$

\begin{tabular}{l}
0 \\
8 \\
\hline \\
\hline
\end{tabular}

$\stackrel{\vec{F}}{\stackrel{9}{9}}$

흠

क़

क

。

$\overrightarrow{\vec{\omega}}$

을

웅

กิำ

옴

ज్

윽

$\vec{D}$

$\stackrel{2}{2}$

N

ㅁํำ

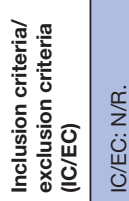
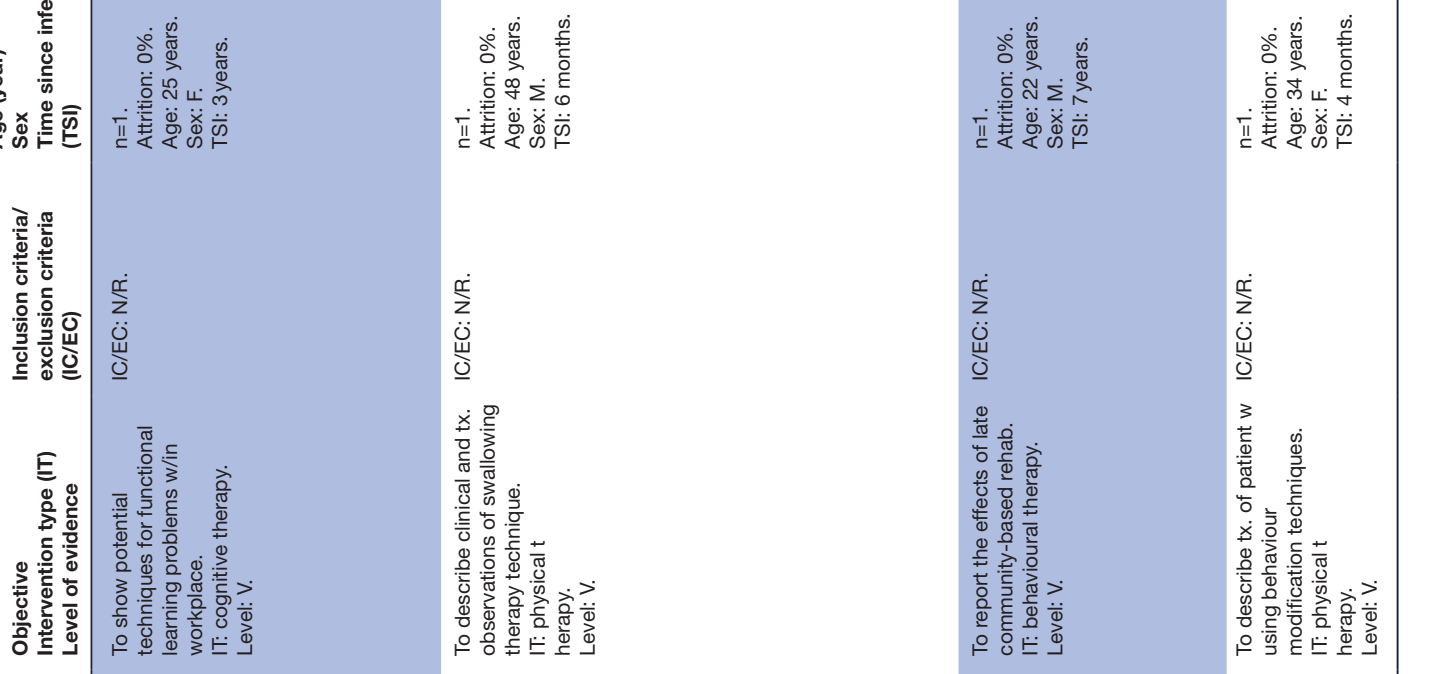

疍

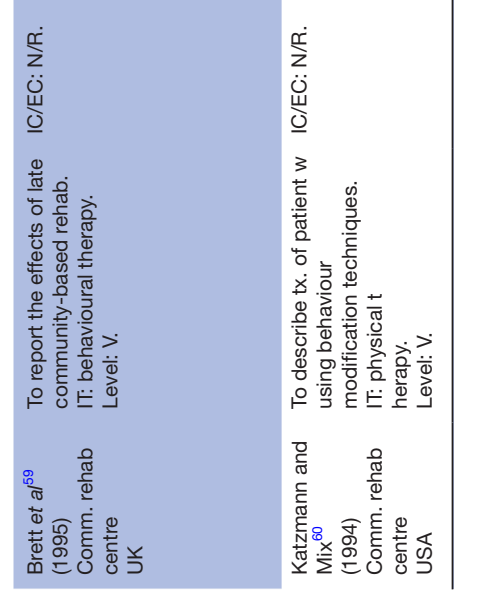

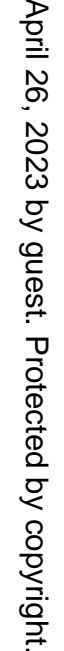




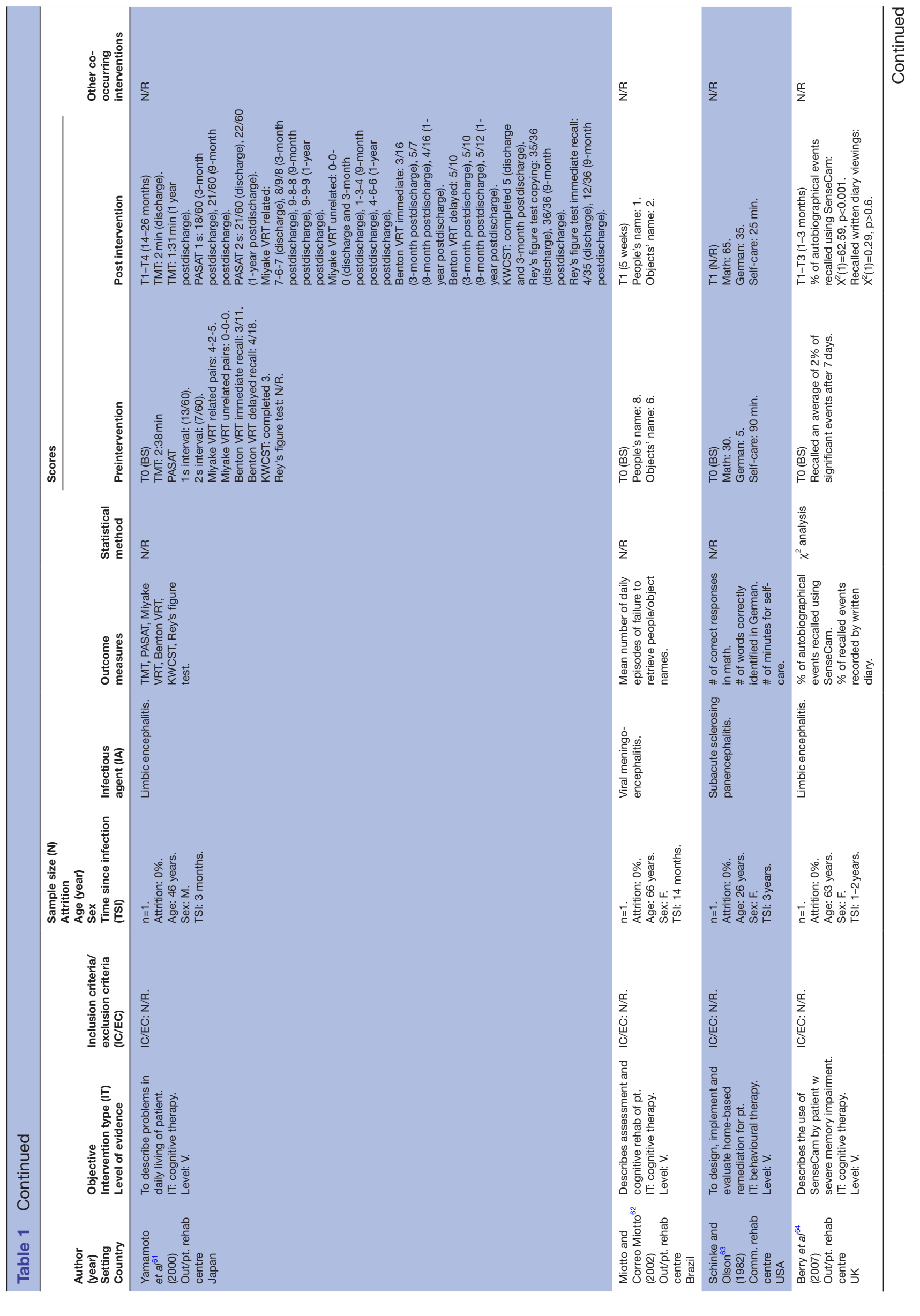

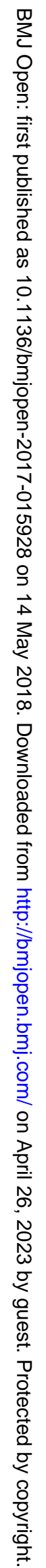




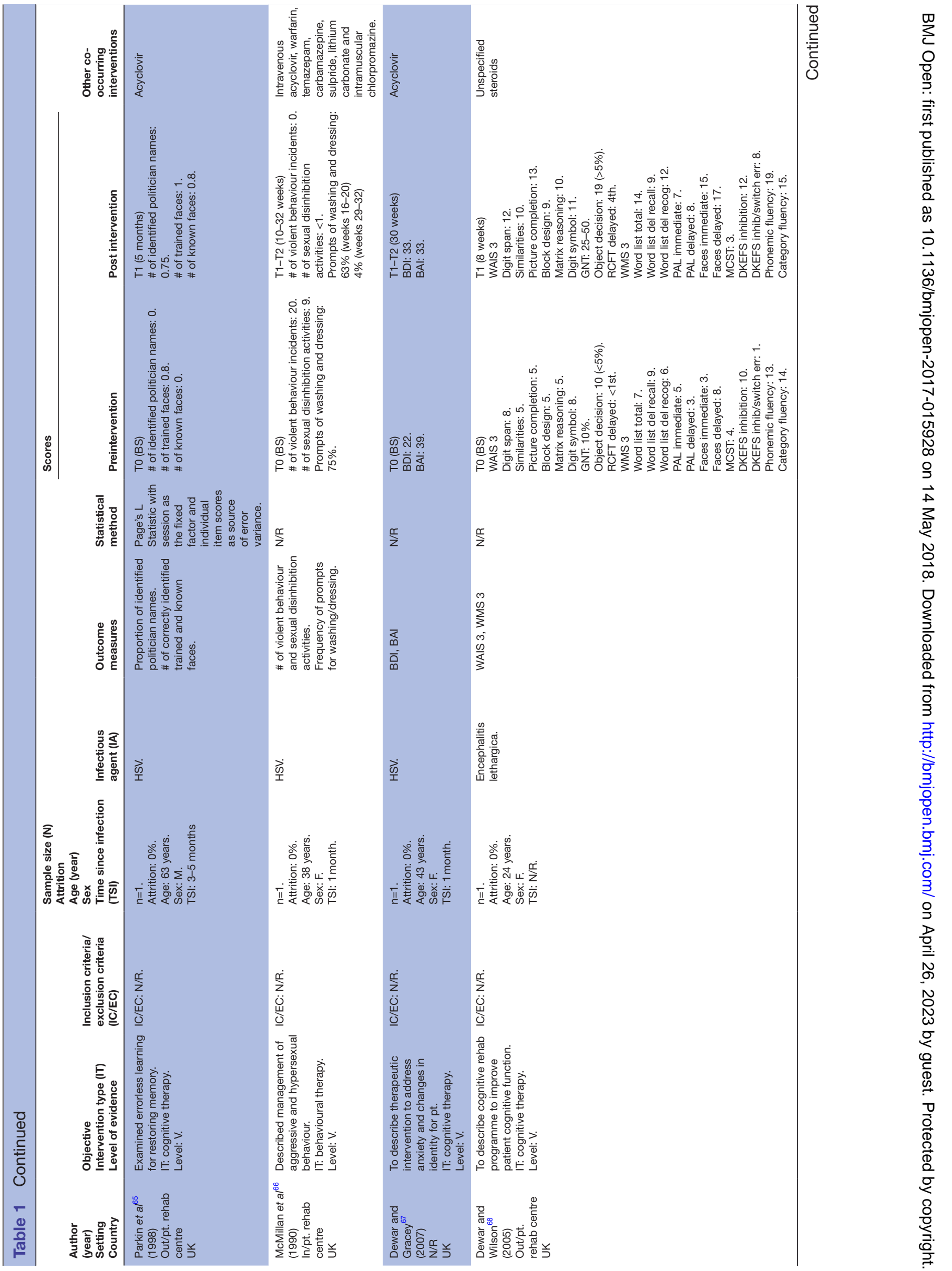




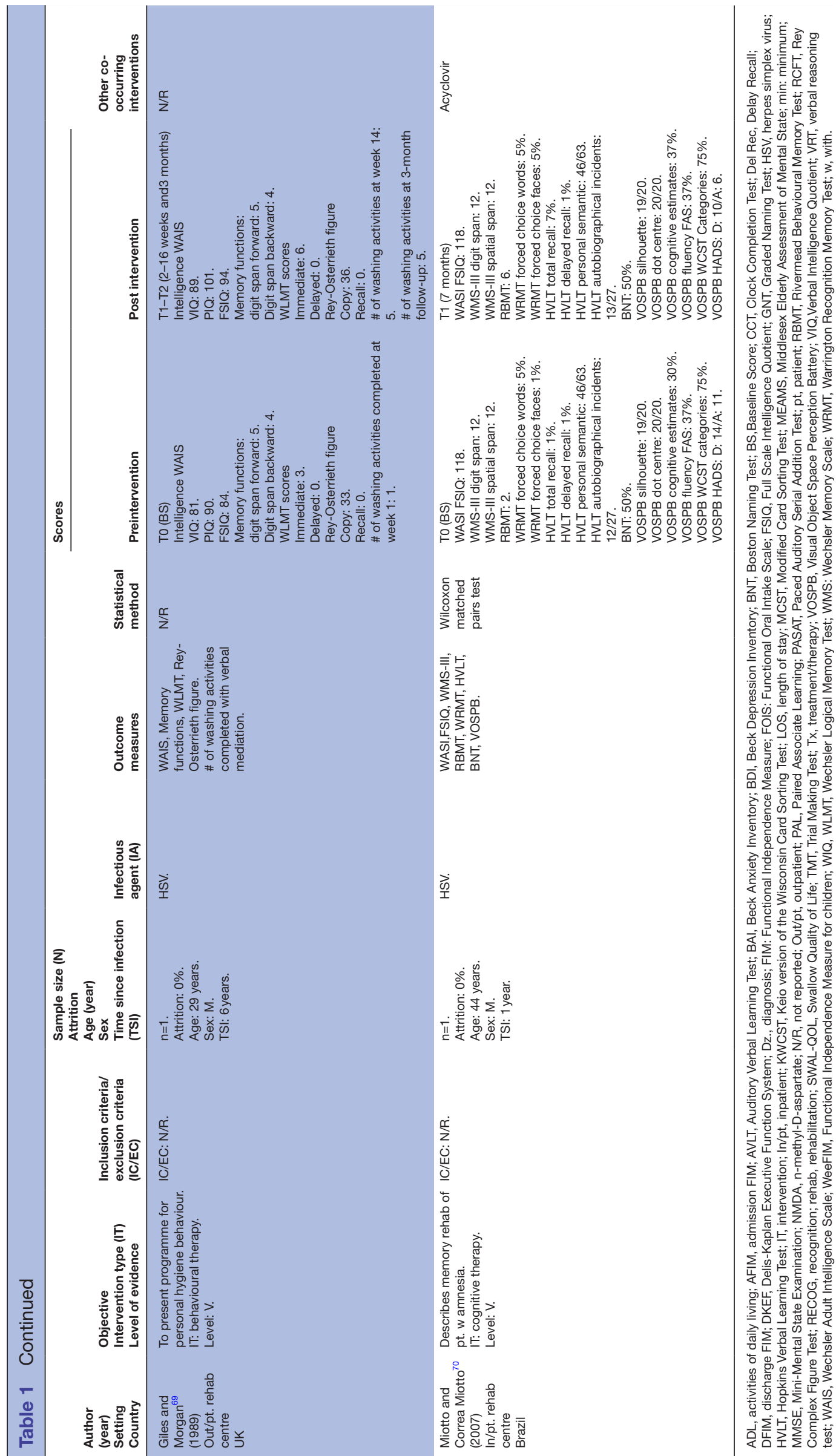




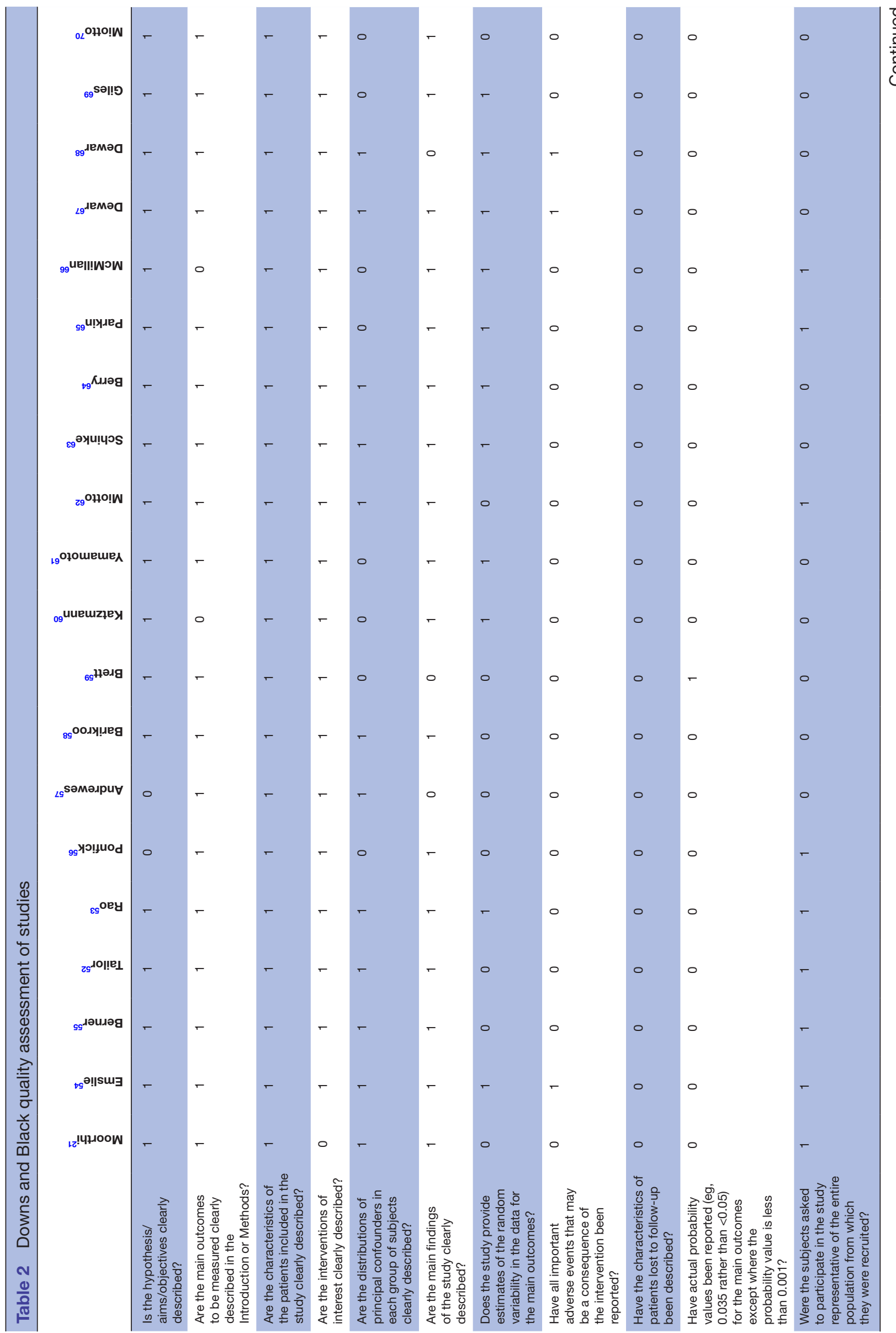

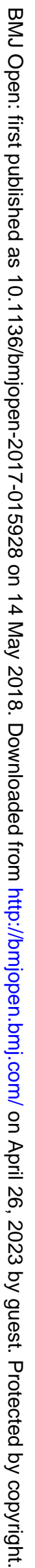




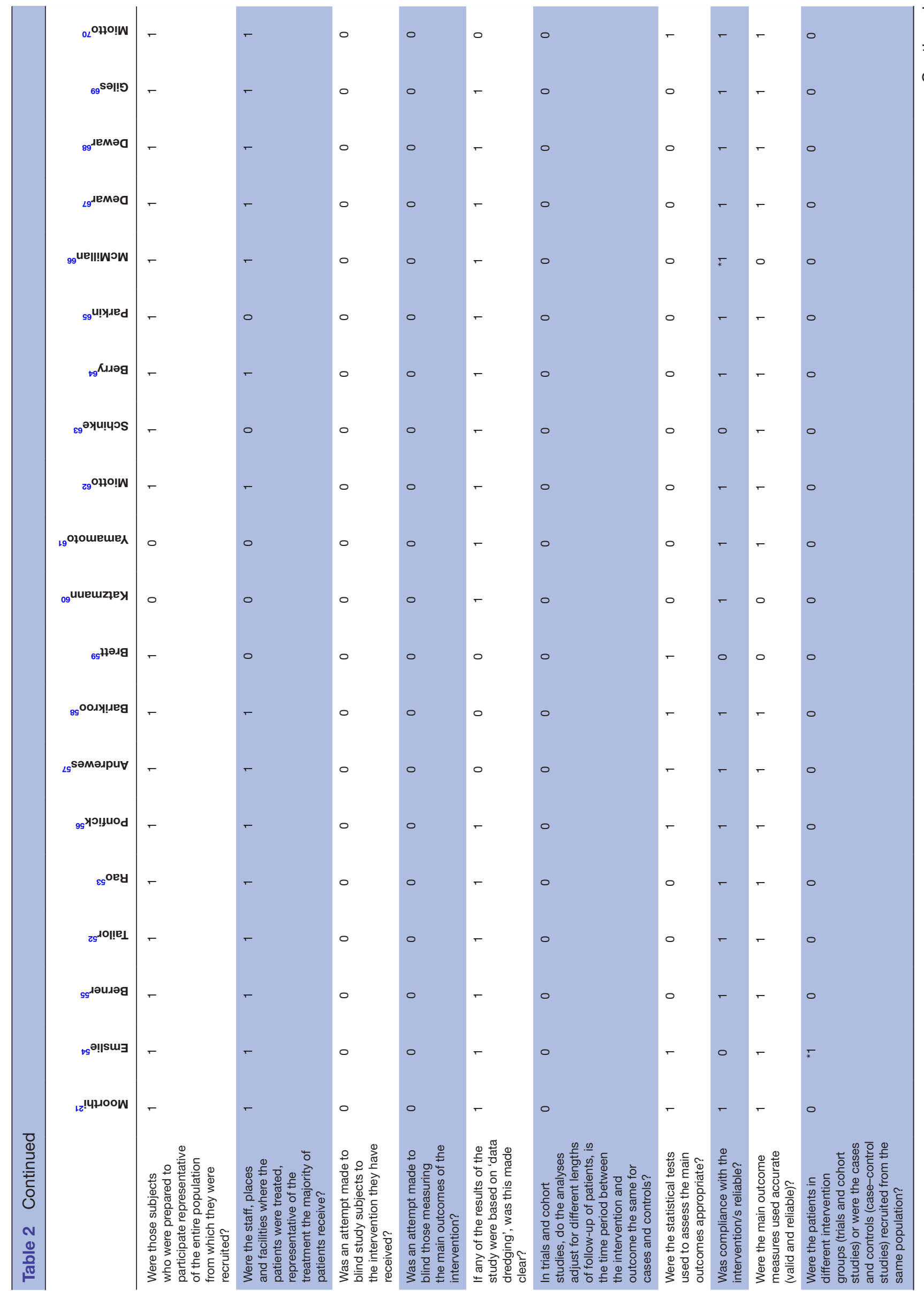

을 


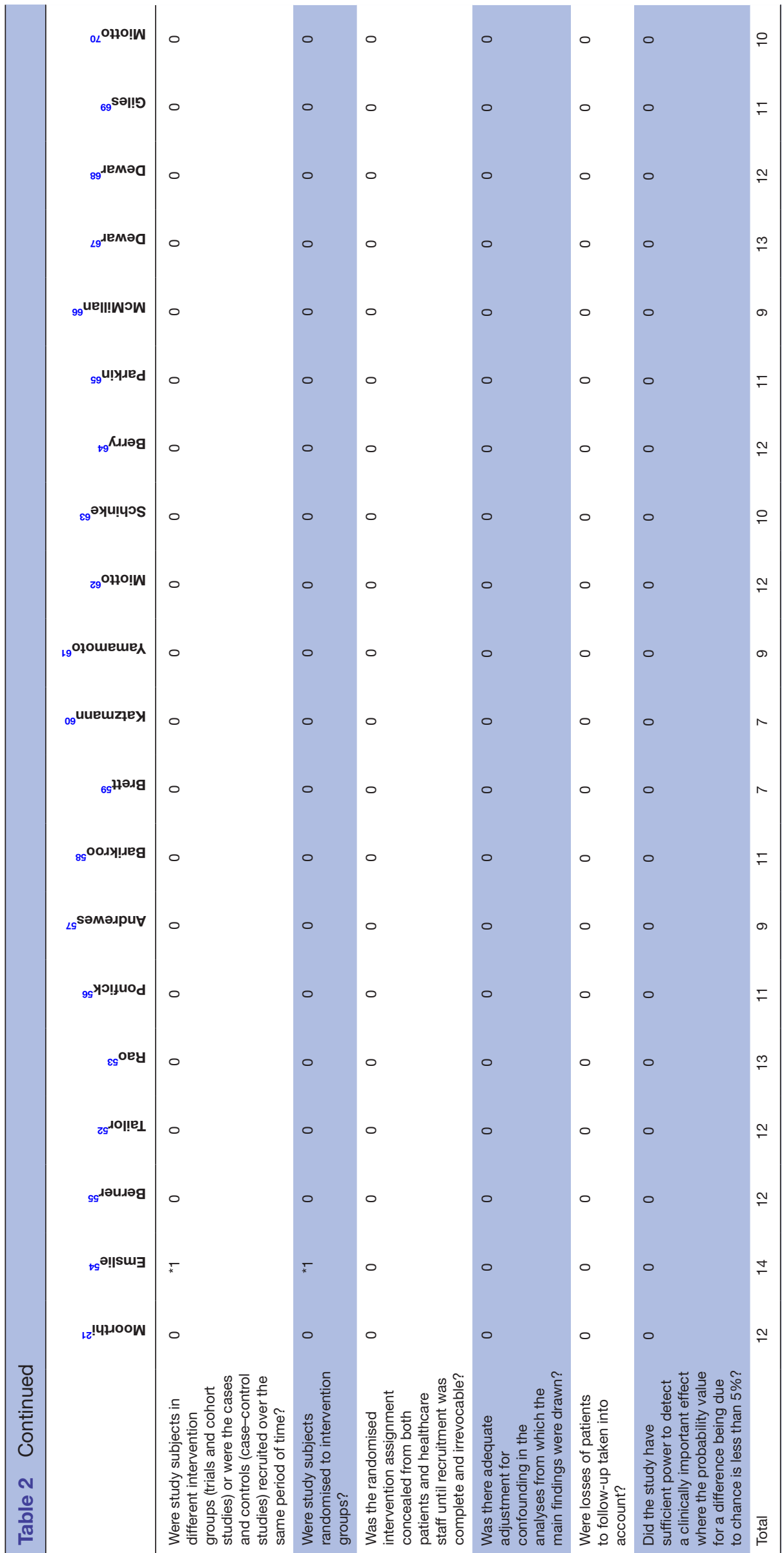

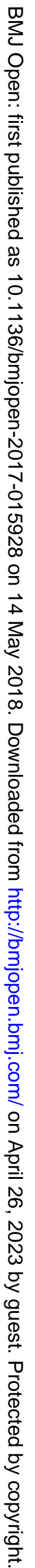


at the baseline assessment, including level of cognitive ability or severity of amnesia due to encephalitis and the follow-up assessment. ${ }^{21} 576064-6870$ Ten studies did not provide information on the assessment tool used to evaluate the severity of deficits experienced by the patient at the baseline. ${ }^{54} 55585961-646970$

Rehabilitation outcomes were reported using functional measures, ${ }^{21} \quad 56 \quad 58$ neuropsychological-based measures,${ }^{55616768}$ behaviour-based measures,${ }^{5460}$ a combination of both functional and neuropsychological test scores (ie, specific to applied intervention), ${ }^{53} 59$ a combination of measures specific to the intervention and neuropsychological measures ${ }^{66}{ }^{69}$ a combination of all three measures of rehabilitation outcomes (ie, neurological test scores, behaviour based measures and functional measures) ${ }^{62}$ and measures only specific to the intervention. ${ }^{63-65} 70$

\section{Intervention outcome by age, sex, intervention type and baseline status}

Differences in outcome of intervention by age ( $\leq 19$ years and $>19$ years)

In the lone study ${ }^{21}$ that included both paediatric and adult patients, the paediatric patient with an admission Functional Independence Measure (AFIM) score of less than 30 demonstrated a longer rehabilitation length of stay (RLOS) and a greater Functional Independence Measure (FIM) efficiency (defined as mean FIM gain from admission to discharge/mean RLOS) in comparison with the adults who displayed AFIM scores at less than 30. No other studies reported age-stratified results.

\section{Differences in outcome of interventions by sex}

Within the included studies, six studies featured both female and male participants. ${ }^{2152-56}$

One study from a paediatric setting reported that the female showed an increase in the WeeFIM scores of cognitive functioning and performance from admission to discharge (26-65), while the two males in the study did not demonstrate a consistency in improvement during inpatient rehabilitation. ${ }^{52}$ In another cohort study, every male showed improvement in the FIM scores from admission to discharge with a score increase between 22 points and 41 points; the two females showed an increased in the FIM score from 37 at admission to 47 at discharge. ${ }^{21}$ In a case series measuring functional items, findings showed that the male participant improved on five functional items, while the female participant improved on eight items. ${ }^{53}$ Another study, however, reported no significant difference in functional outcome between sexes, with both male and female participants demonstrating similar patterns of achieved targets throughout the intervention course.$^{54}$ Lastly, in a study including geriatric participants ( $>65$ years old), all patients (four females and one male) showed an increase in the FIM score from admission to discharge, an increase of 8-46 points for the females and a 40-point increase for the male patient. ${ }^{55}$
Differences in outcomes by intervention type

\section{Cognitive therapy interventions}

Nine studies used cognitive therapy interventions to address cognitive deficits with the efficacy of intervention benefits established through the changes in scores on neuropsychological tests from the baseline to follow-up..$^{5661626465676870}$ In five of the nine studies, positive changes were observed in cognitive measures' scores demonstrated by test item scores (ie, memory retention and language processing) from preintervention to postintervention. ${ }^{6164656768}$ Nevertheless, some neurological deficits persisted on participants' completion of the rehabilitation intervention. ${ }^{61} 64656768$ One study reported success in achieving the intervention's stated goals; however, there was no significant score difference documented at follow-up when compared with the neuropsychological measures at baseline. ${ }^{62}$ Two other studies reported to achieve their stated goals immediately on completion of the intervention; there was no follow-up to assess the sustainability of achieved results. ${ }^{57} 70$ Lastly, one study highlighted that the neurological rehabilitation intervention does not guarantee complete recovery for the majority of patients. ${ }^{56}$

\section{Behavioural therapy interventions}

Five studies described interventions targeting behavioural deficits of patients following a diagnosis of infectious encephalitis. ${ }^{54} 59636669$ Of these, one study reported that all targeted goals set for their patients at the baseline were achieved at the discharge. ${ }^{63}$ The other four studies showed improved outcomes among patients on intervention completion and at various follow-up points (5 weeks, ${ }^{54} 3$ months ${ }^{66} 69$ and 6 years after rehabilitation intervention). ${ }^{59}$

\section{Physical therapy interventions}

Two studies with focus on physical therapy interventions reported improved motor and sensory function scores from the baseline to follow-up; one study demonstrated excellent outcomes on the $3 \mathrm{oz}$ water swallow test, functional oral intake scale and the swallow quality of life questionnaire ${ }^{58}$ and the other study demonstrated lower need of assistance to support activities of daily living. ${ }^{60}$ No long-term follow-up was conducted for either study. ${ }^{58} 60$

\section{Combined therapy interventions}

Four studies applied combined therapies simultaneously (ie, physical, behavioural, and cognitive rehabilitation) to address neurological sequelae of patients with infectious encephalitis. ${ }^{21525355}$ Two cohort studies used neuropsychological and functional status measures for their indicators of rehabilitation interventions' efficacy. ${ }^{21} 57$ Both studies reported participants showed score improvement on all functional and neuropsychological measures from preintervention to postintervention. ${ }^{21} 57$ Two other studies using a combination of physical, occupational, speech and psychology therapy found that patients showed significant improvement in scores at the end of 
treatment compared with baseline scores; however, at the time of follow-up, the majority of patients did not return to normal function and still showed perceptual and cognitive impairments. ${ }^{53}$

\section{Differences in effectiveness of interventions by rehabilitation baseline status}

Nine studies did not study whether the level of functioning at the baseline had an influence on the intervention outcome. One study reported associations between baseline functional scores with discharge destination from rehabilitation setting. ${ }^{21}$ In three studies, authors reported that the level of cognitive capacity prior to the intervention was conducive to the success of intervention goals. ${ }^{576270}$ Two studies attributed the outcome of rapid recovery to the short time since infection (TSI).$^{53} 68$ Another study attributed a patient's severe cognitive, communicative and behavioural impairments at discharge to a longer TSI. ${ }^{53} \mathrm{In}$ a behaviour therapy-based intervention, however, several researchers felt that the rehabilitative interventions were introduced too early, and the patient's anxiety of a new therapy could have hindered its successfulness. ${ }^{54}$

\section{DISCUSSION}

We conducted a systematic review in order to investigate the effectiveness of rehabilitation interventions to assist with neurological sequelae of infectious encephalitis and determine the prognostic value of demographic, clinical and therapy-specific features on rehabilitation outcomes. Of the 20 primary research articles evaluated, all studies at least partially addressed sources of potential study biases, but none of the studies scored more than $50 \%$ on the Downs and Black rating scale. All studies suggest a beneficial effect of rehabilitation interventions in a variety of settings among paediatric and adult patients with infectious encephalitis, with several studies highlighting incomplete recovery and persistence of residual impairments on completion of rehabilitation intervention. We did not find clear evidence of the effect of age, sex, type of infectious agent or intervention type on the effectiveness of rehabilitation intervention in patients with infectious encephalitis.

The majority of included studies that had a low level of evidence (ie, clinical cases and case series) reinforce the consensus within the brain injury rehabilitation community that there is an increasing need for stronger evidence (ie, randomised trials) on treatment effectiveness. ${ }^{71}$ The paucity of good quality intervention studies in patients with infectious encephalitis may be explained by challenges in establishing a diagnosis (ie, patients with infectious encephalitis frequently demonstrate sight and symptoms similar to other generalised brain disorders, and many are likely missed in the acute care), response to medical management, the variability in the clinical picture (impaired motor/movement and/or sensory integrity, arousal and/or attention level and so on) as well as the patient's unique central nervous system characteristics and the degree of inflammation produced by the infection agent. The specifics of individual impairments stemming from infectious encephalitis requires, therefore, a thorough baseline evaluation and development of interventions that are extremely dependent of individual patients' need and, as such, an adaptive study methodology that is reflective of both the natural course of the infection and the magnitude of change from each episode of the intervention process and across the continuum of interventions.

With regards to differing treatment outcomes between children and adult patients, ageing has been one of many other factors that may influence effectiveness of rehabilitation intervention and recovery. Discussion on this topic is limited, as only one study ${ }^{21}$ demonstrated that having a younger age during the time of treatment and presumably time of brain injury may possibly be a protective factor on the outcome of encephalitis. Studies from other populations with generalised brain pathology (ie, TBI) have also highlighted younger age groups showing a greater magnitude of improvement throughout the course of rehabilitation when compared with an older patient groups. ${ }^{35} 36$ Age at time of injury has been suggested to have a noteworthy impact on functional and cognitive recovery of TBI. ${ }^{72-74}$ This impact of age might be explained by the higher developmental ability of the young brain, where deficits of injuries can be compensated by progressing developmental, reorganisation and myelination processes. ${ }^{75}$ To illustrate such, a previous study found children with total functional dependence due to severe brain injuries still have the ability to make significant functional gains at discharge and afterwards. ${ }^{75}$ As such, future studies are needed to provide a comprehensive discussion on the age as it relates to the peak of the immune response to infectious encephalitis, capacity to respond to intervention and recovery time frames.

The included studies in our review also displayed the use of different combinations of intervention techniques, making it problematic to draw conclusions with respect to what type of intervention is generally more effective. For the majority of interventions using cognitive and behavioural-based techniques, there was an overall positive effect on rehabilitation outcome measures at differing follow-up points. However, residual impairments persisted. Compared with outcomes of rehabilitation interventions conducted in other brain injury populations where heterogeneous interventions types are also present, there is substantial evidence to support cognitive rehabilitation for people with TBI and have since created practice guidelines based on this evidence. ${ }^{76} 77$ This may be useful for clinicians when developing treatment plans for patients with encephalitis patients in need of cognitive remediation as both TBI and non-TBI patients similarly go through changes in neuronal activity, which affects the physical integrity, the metabolic activity and the functional ability of the cells. ${ }^{78}$

Studies that reported on patients' baseline status noted that higher baseline scores demonstrating greater 
cognitive capacity might have a positive influence to the intervention outcome. This finding coincides with literature stating that premorbid conditions (eg, learning disability), comorbidities (eg, stress-related psychotic disorders) and socioenvironmental contextual factors prior to rehabilitation can affect the cognitive and functional recovery from a TBI. ${ }^{79}$ These were noted by authors as three relevant factors that may interfere with an individual's response to rehabilitation following a TBI. ${ }^{79}$ Additional research on individuals with a non-TBI, including encephalitis, is needed to determine the specific effect of baseline functioning on recovery.

The evidence remains inconclusive for sex differences in relation to encephalitis recovery, as available data from included studies do not suggest a trending difference of rehabilitation outcomes between the sexes.

\section{LIMITATIONS}

The findings of this systematic review should be considered in the context of several limitations: quality of evidence, heterogeneity of studies and natural process of recovery. First, all studies were rated as having less than 15 out of 31 points based on the Downs and Black rating scale. This review had no studies that used an RCT design, but rather the majority of included studies were case reports/series with small sample sizes (less than 25 patients). This level of evidence demonstrated within the included studies presents limited data to demonstrate the effectiveness of the included interventions and therefore make it difficult to develop strong conclusions for the efficacy of rehabilitation strategies to the encephalitis population for a longer time span. For future research, studies should consider applying higher quality methodological designs to take into account the heterogeneity of patient characteristics in rehabilitation settings.

As mentioned previously, another limitation to this review is the heterogeneity of the study populations. Comparing populations with different aetiologies of infectious encephalitis (ie, difference in infectivity and pathogenicity), varying timespans from the beginning of infection and the use of diverse assessments tools to measure functional gains may make it difficult to make conclusive remarks on which rehabilitative interventions is most effective.

An additional limitation of the included studies is the heterogeneity of age between patients and the lack of studies to stratify this analysis by age as the results cannot display the differences in clinical manifestations and outcomes between infants and older children with encephalitis. This varying difference can also be said for the adult population when comparing the brain recovery of young adults and elderly patients. This is an important area for future research and, as such, future studies should consider using subclasses for these age categorisations when analysing rehabilitation outcomes.

Lastly, an inherent limitation of conducting and reporting rehabilitation outcomes is the possibility of natural process of recovery and the differing needs of individual patients that may influence the rehabilitation outcomes ${ }^{51}$ following encephalitis. This factor can impact the success of rehabilitation and may not be necessarily accounted for or captured throughout the case series/ studies described in this review. This limiting factor in current studies highlights the need for comparison groups in the future.

\section{IMPLICATIONS}

In all, there are certain implications that can be taken from this review on outcomes of rehabilitation interventions focused on infectious encephalitis. The findings of our review corroborate the need for strong randomised, blinded and controlled research designs including large prospective studies to follow this patient population until maximal recovery is achieved, standardisation of measures and adequate statistical analysis. ${ }^{80}$ Of additional benefit would be studies spanning internationally, taking into account the capacities of different healthcare systems when addressing rehabilitation care for encephalitis.

\section{CONCLUSION}

Our findings point to the potential benefit of several interventions focused on rehabilitation after a diagnosis of infectious encephalitis in improving functionality. There is, however, a need for research focused on evaluation of the effectiveness of such interventions in larger scale prospective studies to disentangle improvement by rehabilitation treatment and that by natural processes over time.

Acknowledgements We would like to thank Jessica Babineau, an information specialist at TRI-UHN, for her assistance with developing and reviewing the search strategy.

Contributors SC and VC conceptualised the study objective and formulated the design of the search strategy. TM critically reviewed the search strategy and codeveloped with SC the analysis approach. VC assisted with the development of the search terms. SC and TM selected and appraised studies for analysis. SC performed analysis and interpretation of data. SC drafted the manuscript. All authors contributed to the critical revision of the manuscript for important intellectual content. All authors read and approved the final manuscript.

Funding This work was supported by AC through the Canadian Institute of Health Research (CIHR) Chair in Gender Work and Health (\#CWG-126580). VC received support from the CIHR and Pediatric Oncology Group of Ontario for a Doctoral Research Award, Brain Canada and CIBC for a Brain Cancer Training Award and the Ontario Neurotrauma Foundation for the Jane Gillett Pediatric ABI Studentship. TM received support by the Alzheimer's Association research fellowship grant (AARF-16-442937).

Competing interests None declared.

Patient consent Not required.

Provenance and peer review Not commissioned; externally peer reviewed. Data sharing statement № additional data available.

Open Access This is an Open Access article distributed in accordance with the Creative Commons Attribution Non Commercial (CC BY-NC 4.0) license, which permits others to distribute, remix, adapt, build upon this work non-commercially, and license their derivative works on different terms, provided the original work is properly cited and the use is non-commercial. See: http://creativecommons.org/ licenses/by-nc/4.0/ 
(c) Article author(s) (or their employer(s) unless otherwise stated in the text of the article) 2018. All rights reserved. No commercial use is permitted unless otherwise expressly granted.

\section{REFERENCES}

1. National Institute of Neurological Disorders and Stroke (NINDS). Meningitis and encephalitis fact sheet. http://www.ninds.nih.gov/ disorders/encephalitis_meningitis/detail_encephalitis_meningitis.htm (accessed 15 Dec 2015).

2. Association of American Medical Colleges. Infectious Disease, Internal Medicine. https://www.aamc.org/cim/specialty/list/us/ 339608/infectious_disease_-internal_medicine.html (accessed 19 Nov 2015).

3. George BP, Schneider EB, Venkatesan A. Encephalitis hospitalization rates and inpatient mortality in the United States, 2000-2010. PLoS One 2014;9:e104169.

4. Khetsuriani N, Holman RC, Anderson LJ. Burden of encephalitisassociated hospitalizations in the United States, 1988-1997. Clin Infect Dis 2002;35:175-82

5. Kulkarni MA, Lecocq AC, Artsob $\mathrm{H}$, et al. Epidemiology and aetiology of encephalitis in Canada, 1994-2008: a case for undiagnosed arboviral agents? Epidemiol Infect 2013;141:2243-55.

6. Granerod J, Ambrose HE, Davies NW, et al. Causes of encephalitis and differences in their clinical presentations in England: a multicentre, population-based prospective study. Lancet Infect Dis 2010;10:835-44

7. Granerod J, Cousens S, Davies NW, et al. New estimates of incidence of encephalitis in England. Emerg Infect Dis 2013;19:1455-62.

8. Corrigan JD, Selassie AW, Orman JA. The epidemiology of traumatic brain injury. J Head Trauma Rehabil 2010;25:72-80.

9. Faul M, Xu L, Wald MM, et al. Traumatic brain injury in the United States. Atlanta, GA: National Center for injury Prevention and Control, Centers for disease Control and Prevention, 2010.

10. Rutland-Brown W, Langlois JA, Thomas KE, et al. Incidence of traumatic brain injury in the United States, 2003. J Head Trauma Rehabil 2006;21:544-8.

11. Chen A, Bushmeneva K, Zagorski B, et al. Direct cost associated with acquired brain injury in Ontario. BMC Neurol 2012;12:12:1.

12. Vora NM, Holman RC, Mehal JM, et al. Burden of encephalitisassociated hospitalizations in the United States, 1998-2010. Neurology 2014;82:443-51.

13. Granerod J, Crowcroft NS. The epidemiology of acute encephalitis. Neuropsychol Rehabil 2007;17:406-28.

14. Khandaker G, Jung J, Britton PN, et al. Long-term outcomes of infective encephalitis in children: a systematic review and metaanalysis. Dev Med Child Neurol 2016;58:1108-15.

15. Fowler A, Stödberg T, Eriksson M, et al. Long-term outcomes of acute encephalitis in childhood. Pediatrics 2010;126:e828-35.

16. Modi S, Mahajan A, Dharaiya D, et al. Burden of herpes simplex virus encephalitis in the United States. J Neurol 2017;264:1204-8.

17. Ilias A, Galanakis E, Raissaki M, et al. Childhood encephalitis in Crete, Greece. J Child Neurol 2006;21:910-2.

18. Kolski H, Ford-Jones EL, Richardson S, et al. Etiology of acute childhood encephalitis at The Hospital for Sick Children, Toronto, 1994-1995. Clin Infect Dis 1998;26:398-409.

19. Wang IJ, Lee PI, Huang LM, et al. The correlation between neurological evaluations and neurological outcome in acute encephalitis: a hospital-based study. Eur J Paediatr Neurol 2007:11:63-9.

20. Mailles A, De Broucker T, Costanzo P, et al. Long-term outcome of patients presenting with acute infectious encephalitis of various causes in France. Clin Infect Dis 2012;54:1455-64.

21. Moorthi S, Schneider WN, Dombovy ML. Rehabilitation outcomes in encephalitis--a retrospective study 1990-1997. Brain Inj 1999;13:139-46.

22. Wong V, Yeung CY. Acute viral encephalitis in children. J Paediatr Child Health 1987;23:339-42.

23. Tong CYW, Potter FA, Pang KA, et al. Severe encephalitis with rapid recovery. The Lancet 1997;349:470.

24. Zifroni A, Fried M, Shalmon B, et al. Severe encephalitis with rapid recovery. The Lancet 1997;349:1328.

25. Fowler $\AA$, Forsman L, Eriksson M, et al. Tick-borne encephalitis carries a high risk of incomplete recovery in children. $J$ Pediatr 2013;163:555-60.

26. Lowry PW. Arbovirus encephalitis in the United States and Asia. $J$ Lab Clin Med 1997;129:405-11.
27. Zhao W, An Z, Hong Y, et al. Sex differences in long-term outcomes among acute ischemic stroke patients with diabetes in China. Biol Sex Differ 2015;6:1.

28. Mehndiratta P, Wasay M, Mehndiratta MM. Implications of female sex on stroke risk factors, care, outcome and rehabilitation: an Asian perspective. Cerebrovasc Dis 2015;39:302-8.

29. Peterson BL, Won S, Geddes RI, et al. Sex-related differences in effects of progesterone following neonatal hypoxic brain injury. Behav Brain Res 2015;286:152-65.

30. Breslau N, Davis GC, Andreski $P$, et al. Sex differences in posttraumatic stress disorder. Arch Gen Psychiatry 1997;54:1044-8.

31. Kappus RM, Ranadive SM, Yan $\mathrm{H}$, et al. Sex differences in autonomic function following maximal exercise. Biol Sex Differ 2015;6:1.

32. Zhou Y, Zhao M, Zhou C, et al. Sex differences in drug addiction and response to exercise intervention: From human to animal studies. Front Neuroendocrinol 2016;40:24-41.

33. Osika Friberg I, Krantz G, Määttä S, et al. Sex differences in health care consumption in Sweden: A register-based cross-sectional study. Scand J Public Health 2016;44:264-73.

34. Mosenthal AC, Lavery RF, Addis M, et al. Isolated traumatic brain injury: age is an independent predictor of mortality and early outcome. J Trauma 2002;52:907-11.

35. Hukkelhoven CW, Steyerberg EW, Rampen AJ, et al. Patient age and outcome following severe traumatic brain injury: an analysis of 5600 patients. J Neurosurg 2003;99:666-73.

36. Dahdah MN, Barnes S, Buros A, et al. Variations in inpatient rehabilitation functional outcomes across centers in the traumatic brain injury model systems study and the influence of demographics and injury severity on patient outcomes. Arch Phys Med Rehabil 2016;97:1821-31.

37. Jimenez N, Osorio M, Ramos JL, et al. Functional independence after inpatient rehabilitation for traumatic brain injury among minority children and adolescents. Arch Phys Med Rehabil 2015;96:1255-61.

38. Turner-Stokes L, Disler PB, Nair A, et al. Multi-disciplinary rehabilitation for acquired brain injury in adults of working age. Cochrane Database Syst Rev 2005;3:CD004170.

39. Slavin RE. Best evidence synthesis: an intelligent alternative to metaanalysis. J Clin Epidemiol 1995;48:9-18.

40. Moher D, Liberati A, Tetzlaff J, et al. Preferred reporting items for systematic reviews and meta-analyses: the PRISMA statement. Ann Intern Med 2009;151:264-9.

41. Christie S, Chan V, Mollayeva T, et al. Rehabilitation interventions in children and adults with infectious encephalitis: a systematic review protocol. BMJ Open 2016;6:e010754.

42. World Health Organization. Rehabilitation health. http://www.who.int/ topics/ rehabilitation/en/2015 (accessed 23 Jun 2015).

43. Khuu W, Chan V, Colantonio A. A systematic review protocol for measuring comorbidity in inpatient rehabilitation for non-traumatic brain injury. Syst Rev 2015;4:1.

44. Rohling ML, Faust ME, Beverly B, et al. Effectiveness of cognitive rehabilitation following acquired brain injury: a meta-analytic reexamination of Cicerone et al.'s $(2000,2005)$ systematic reviews. Neuropsychology 2009;23:20-.

45. GL'99 Conference Program. Fourth International Conference on Grey Literature: New Frontiers in Grey Literature. Washington DC, USA: GreyNet, Grey Literature Network Service, 1999:4-5.

46. Mollayeva T, Kendzerska T, Mollayeva S, et al. A systematic review of fatigue in patients with traumatic brain injury: the course, predictors and consequences. Neurosci Biobehav Rev 2014;47:684-716.

47. World Health Organization. Definition of key terms. http://www.who. int/hiv/pub/ guidelines/arv2013/intro/keyterms/en/.

48. World Health Organization. Adolescent health. http://www.who.int/ topics/adolescen t_health/en/ (accessed 17 Nov 2015).

49. Downs $\mathrm{SH}$, Black $\mathrm{N}$. The feasibility of creating a checklist for the assessment of the methodological quality both of randomised and non-randomised studies of health care interventions. J Epidemiol Community Health 1998;52:377-84.

50. Eng JJ, Teasell R, Miller WC, et al. Spinal cord injury rehabilitation evidence: methods of the SCIRE systematic review. Top Spinal Cord Inj Rehabil 2007;13:1-10.

51. Teasell R, Bayona N, Marshall S, et al. A systematic review of the rehabilitation of moderate to severe acquired brain injuries. Brain Inj 2007;21:107-12.

52. Tailor YI, Suskauer SJ, Sepeta LN, et al. Functional status of children with encephalitis in an inpatient rehabilitation setting: a case series. $J$ Pediatr Rehabil Med 2013;6:163-7.

53. Rao N, Costa JL. Rehabilitation of three patients after treatment for herpes encephalitis. Am J Phys Med Rehabil 1991;70:73-5.

54. Emslie H, Wilson BA, Quirk K, et al. Using a paging system in the rehabilitation of encephalitic patients. Neuropsychol Rehabil 2007;17:567-81. 
55. Berner Y, Feldman J, Spigel D, et al. Rehabilitation of West Nile Fever (WNF) encephalitis in elderly. Arch Gerontol Geriatr 2005;41:15-21.

56. Ponfick M, Hacker S, Gdynia HJ, et al. Meningoencephaloradiculomyelitis after tick-borne encephalitis virus infection: a case series. Eur J Neurol 2012;19:776-82.

57. Andrewes $D$. The work rehabilitation of a herpes simplex encephalitis patient with anterograde amnesia. Neuropsychol Rehabil 1999;9:77-99.

58. Barikroo A, Lam PM. Comparing the effects of rehabilitation swallowing therapy vs. functional neuromuscular electrical stimulation therapy in an encephalitis patient: a case study. Dysphagia 2011;26:418-23.

59. Brett M, Greenwood R, Powell J, et al. Late functional recovery with a novel community rehabilitation programme after herpes simplex encephalitis. Clin Rehabil 1995:9:267-70.

60. Katzmann S, Mix C. Improving functional independence in a patient with encephalitis through behavior modification shaping techniques. Am J Occup Ther 1994;48:259-62.

61. Yamamoto E, Izumi SI, Shimakura K, et al. Memory rehabilitation of an amnesic patient following limbic encephalitis and a role of family members: a case report. Tokai J Exp Clin Med 2000;25:173-81.

62. Miotto EC, Correa Miotto E. Cognitive rehabilitation of naming deficits following viral meningo-encephalitis. Arq Neuropsiquiatr 2002;60:21-7.

63. Schinke SP, Olson DG. Home remediation of subacute sclerosing panencephalitis. Education and Treatment of Children 1982:261-9.

64. Berry E, Kapur N, Williams L, et al. The use of a wearable camera, SenseCam, as a pictorial diary to improve autobiographical memory in a patient with limbic encephalitis: a preliminary report. Neuropsychol Rehabil 2007;17:582-601.

65. Parkin AJ, Hunkin NM, Squires EJ. Unlearning john major: the use of errorless learning in the reacquisition of proper names following herpes simplex encephalitis. Cogn Neuropsychol 1998;15:361-75.

66. McMillan TM, Papadopoulos H, Cornall C, et al. Modification of severe behaviour problems following herpes simplex encephalitis. Brain Inj 1990;4:399-406.

67. Dewar BK, Gracey F. "Am not was": cognitive-behavioural therapy for adjustment and identity change following herpes simplex encephalitis. Neuropsychol Rehabil 2007;17:602-20.
68. Dewar BK, Wilson BA. Cognitive recovery from encephalitis lethargica. Brain Inj 2005;19:1285-91.

69. Giles GM, Morgan JH. Training functional skills following herpes simplex encephalitis: a single case study. J Clin Exp Neuropsychol 1989;11:311-8.

70. Miotto EC, Correa Miotto E. Cognitive rehabilitation of amnesia after virus encephalitis: a case report. Neuropsychol Rehabil 2007;17:551-66.

71. Whyte J. Traumatic brain injury rehabilitation: are there alternatives to randomized clinical trials? Arch Phys Med Rehabil 2002;83:1320-2.

72. Anderson V, Catroppa C, Morse S, et al. Intellectual outcome from preschool traumatic brain injury: a 5-year prospective, longitudinal study. Pediatrics 2009;124:e1064-e1071.

73. Anderson V, Godfrey C, Rosenfeld JV, et al. Predictors of cognitive function and recovery 10 years after traumatic brain injury in young children. Pediatrics 2012;129:e254-e261.

74. Crowe LM, Catroppa C, Babl FE, et al. Intellectual, behavioral, and social outcomes of accidental traumatic brain injury in early childhood. Pediatrics 2012;129:e262-e268.

75. Kramer ME, Suskauer SJ, Christensen JR, et al. Examining acute rehabilitation outcomes for children with total functional dependence after traumatic brain injury: a pilot study. J Head Trauma Rehabil 2013;28:361-70.

76. Cicerone KD, Dahlberg C, Kalmar K, et al. Evidence-based cognitive rehabilitation: recommendations for clinical practice. Arch Phys Med Rehabil 2000;81:1596-615.

77. Cicerone KD, Dahlberg C, Malec JF, et al. Evidence-based cognitive rehabilitation: updated review of the literature from 1998 through 2002. Arch Phys Med Rehabil 2005;86:1681-92.

78. Giustini A, Pistarini C, Pisoni C. Traumatic and nontraumatic brain injury. Handb Clin Neurol 2013;110:401-9.

79. Institute of Medicine. Cognitive rehabilitation therapy for traumatic brain injury: evaluating the evidence. Washington, DC: The National Academic Press, 2011.

80. Chesnut RM, Carney N, Maynard H, et al. Summary report: evidence for the effectiveness of rehabilitation for persons with traumatic brain injury. J Head Trauma Rehabil 1999;14:176-88. 